This item was submitted to Loughborough's Research Repository by the author.

Items in Figshare are protected by copyright, with all rights reserved, unless otherwise indicated.

\title{
Effect of humic acid on E. coli disinfection in a microbubble-gas plasma reactor
}

PLEASE CITE THE PUBLISHED VERSION

https://doi.org/10.1016/j.jwpe.2019.100881

PUBLISHER

(C) Elsevier

VERSION

AM (Accepted Manuscript)

\section{PUBLISHER STATEMENT}

This paper was accepted for publication in the journal Journal of Water Process Engineering and the definitive published version is available at https://doi.org/10.1016/j.jwpe.2019.100881.

LICENCE

CC BY-NC-ND 4.0

\section{REPOSITORY RECORD}

Wright, Alexander R.P., Bipin Uprety, Alexander H. Shaw, Gilbert Shama, Felipe Iza, and Hemaka Bandulasena. 2019. "Effect of Humic Acid on E. Coli Disinfection in a Microbubble-gas Plasma Reactor". Loughborough University. https://hdl.handle.net/2134/38091. 


\title{
Effect of Humic Acid on $E$. coli Disinfection in a Microbubble-Gas Plasma Reactor
}

\author{
Alexander Wright, ${ }^{\mathrm{a}, \mathrm{b}}$ Bipin Uprety, ${ }^{\mathrm{a}}$ Alex Shaw, ${ }^{\mathrm{b}}$ Gilbert Shama, ${ }^{\mathrm{a}}$ Felipe Iza, ${ }^{\mathrm{b}}$ Hemaka Bandulasena, ${ }^{\mathrm{a}^{*}}$ \\ ${ }^{a}$ Department of Chemical Engineering, Loughborough University, Loughborough, Leicestershire, LE11 \\ 3TU, United Kingdom \\ b Wolfson School of Mechanical, Electrical and Manufacturing Engineering, Loughborough University, \\ Loughborough, Leicestershire, LE11 3TU, United Kingdom
}

*Corresponding author- Email: H.C.H.Bandulasena@lboro.ac.uk, Tel.: +44 (0) 1509222515

\begin{abstract}
Final effluent from wastewater treatment plants may contain bacteria that can pose a range of environmental and health threats. A microbubble-gas plasma reactor capable of producing a number of both reactive oxygen species and reactive nitrogen species has been developed for inactivating bacteria in final effluents. At the optimum operating conditions, greater than 5-log reductions in E. coli viability was achieved in pure water after 30 minutes of operation with an energy consumption of $68 \mathrm{~kJ} / \mathrm{L}$. Addition of humic acid reduced the E. coli inactivation rate. At the highest concentration of humic acid tested $(0.0015 \% \mathrm{w} / \mathrm{w})$, E. coli inactivation was reduced by $\sim 50 \%$ compared to that achieved in pure water for a 30-minute treatment time. Longer treatment times may be required for waste streams having a high organic content, but the disinfection levels achieved with a low power consumption demonstrate the potential of this approach for industrial use.
\end{abstract}

\section{Keywords}

Microbubbles

Gas Plasma

E. coli

Disinfection

Final Wastewater Effluents 


\subsection{Introduction}

There is growing concern over the threat posed by antimicrobial resistant (AMR) bacteria [1], and the World Health Organization (WHO) has issued guidelines for mitigating the threat whilst highlighting the need to looking for novel solutions for dealing with it [2]. Coupled to this is the declining rate in the discovery of new antibiotics. On this basis it has become essential to minimise the transmission of antibiotic resistance genes between bacteria in the environment. Wastewater treatment plants (WWTPs) have been identified as one such source for the spread of AMR bacteria, and disinfection of final effluents constitutes one strategy for mitigating the risks posed [3]. Ozone $\left(\mathrm{O}_{3}\right)$ has been widely applied to wastewater and drinking water treatment for disinfecting final effluents across both Europe and North America [4], but in recent years there has been mounting interest in advanced oxidation processes (AOPs) in order to exploit a wider range of reactive species [5]. AOPs produce hydroxyl radicals $\left(\mathrm{OH}^{\circ}\right)$ - highly reactive species with an oxidation potential superior to that of ozone, which greatly increase the efficiency of the disinfection process [6]. There are numerous AOP variants, but most are based upon the use of ozone, or else employ hydrogen peroxide as oxidant. This may be combined with UV radiation, which while leading to an increase in disinfection efficiency results in increased costs and complexity of the system [7].

An alternative approach for bringing about disinfection is the use of atmospheric pressure plasmas (APP), which generate a wide range of reactive species in addition to UV [8]. APPs have predominantly been investigated for their disinfective properties, making them highly applicable for inactivating microorganisms in wastewater $[9,10]$. Gils and co-workers investigated the inactivation of bacteria suspended in aqueous media by means of an atmospheric pressure plasma jet that generated both reactive oxygen species (ROS) and reactive nitrogen species (RNS) [11]. Their study highlighted the advantages of operating at a low $\mathrm{pH}$ which led to direct bacterial inactivation in addition to that achieved as a result of increased ozone solubility at the $\mathrm{pH}$ employed. The synergistic effects of the reactive species produced by the plasma, such as $\mathrm{ONOO}^{-}, \mathrm{HNO}_{2}$ and $\mathrm{H}_{2} \mathrm{O}_{2}$, on bacterial inactivation was also reported upon highlighting the advantages of APPs over ozone. Laroussi and co-workers used an atmospheric 
plasma produced by means of a resistive barrier discharge (RBD) over a 96-well microtiter plate to investigate its germicidal effects [12]. It was demonstrated that cellular functions were impaired by the plasma species but the extent to which this occurred depended on the type of micro-organism undergoing treatment. E. coli showed severe disruption to its cell wall but no such effects were observed with Bacillus subtilis.

Numerous reactor configurations have been proposed to maximize mass transfer of reactive species into the liquid phase $[10,13]$. With the importance of high rates of mass transfer having been established, a novel microbubble-dielectric barrier discharge (DBD) plasma reactor has been developed to produce a wide range of reactive species in-situ (inside the plenum chamber for aeration) and bringing about their dispersion using microbubbles. The close proximity of the plasma discharge to the gas-liquid interface of the microbubble generation site leads to the transfer of short-lived reactive species from the plasma to the liquid phase increasing process efficacy [14]. Experimental measurement of concentration of short-lived species in the liquid phase is highly challenging; therefore, computational methods are often used to determine their concentration at gas-liquid interfaces [15].

In most previous studies that employed APPs for wastewater treatment, deionized water had been used as the liquid medium - a medium favourable for bacterial inactivation but not representative of actual wastewater effluents $[9,16]$. Both surface and ground waters commonly contain organic compounds resulting from the breakdown of plant and animal matter in soils. The most prevalent of such compounds are fulvic and humic acids neither of which are not removed during conventional WWTP [17]. There is a large variation in both the properties of naturally occurring HA and their concentration in waters. HA typically constitutes between $3-38 \%$ of the dissolved organic matter [18] in final effluents. The HA concentration in wastewaters depends on the source and hence may require changes to be made to the treatment process on this basis.

In the work reported here the effect of dissolved organic matter - humic acid (HA) - on microbial inactivation in a microbubble-plasma reactor of novel configuration was investigated. The micro- 
organism used was E. coli, a bacterium commonly found in final effluents from WWTPs. Operation of the microbubble reactor was conducted with both clean water and water in which HA was dissolved. The latter being so as to emulate final effluents and to establish what effects organic matter would have on the efficacy of disinfection.

\subsection{Materials and methods}

\subsection{Microbubble-gas plasma reactor configuration}

A novel microbubble-gas plasma treatment reactor that facilitates transfer of short-lived reactive species generated by the plasma to the liquid phase was used in this study (Figure 1(a)). A key feature of this reactor configuration is the formation of the DBD plasma discharge at the gas-liquid interface. This is made possible by using a microporous nickel membrane as the sparger as well as the ground electrode (Figure 1(b)). The detailed design and characterization of the reactor have been described in a previous study $[14,19]$, and therefore only a brief description is provided here.

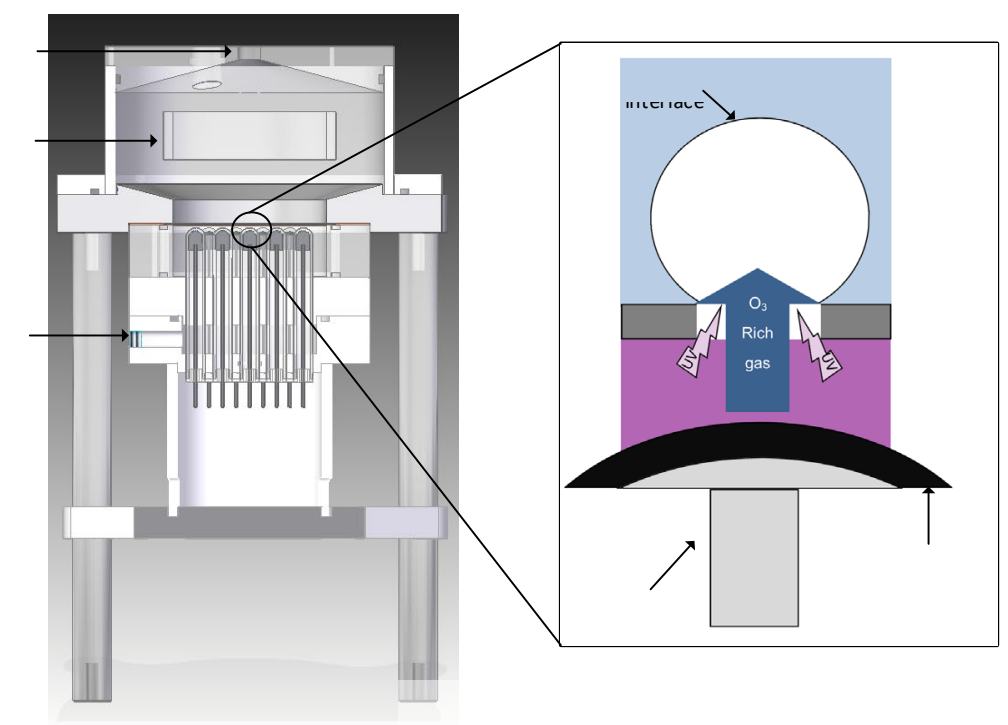

Figure 1: (a) A schematic representation of the microbubble-gas plasma reactor used in this study. (b) The formation of microbubbles in the vicinity of the plasma discharge. 
The internal configuration of the reactor is shown in Figure 1. The high voltage electrode assembly consists of 19 parallel stainless-steel rods, each encased in quartz dielectric crucibles. The inlet gas supply to the plenum chamber is provided through a small orifice located in the base plate. Dry compressed air is supplied to the reactor at 0.5 SLPM via a mass controller. The inlet gas then gets distributed in the receiving chamber by pressure build-up and rises around the gaps between the quartz crucibles to the plenum chamber. A dielectric barrier discharge (DBD) plasma is formed adjacent to the microbubble formation sites, allowing immediate transfer of the reactive species across the gas-liquid interface. The generation of microbubbles having a diameter of the order of $550 \mu \mathrm{m}$ is a key feature of this reactor, as small bubbles provide a high surface to volume ratio increasing the mass transfer efficiency. Another determinant of bubble size was that their release into the liquid phase of the reactor should induce efficient mixing. This was achieved by means of a $20 \mu \mathrm{m}$ pore nickel membrane with a pitch of $180 \mu \mathrm{m}$. To disperse the reactive species into the reaction vessel efficiently (total volume $0.5 \mathrm{~L}$ ) and to induce mixing, a draft tube was introduced to the tank, removing the need for mechanical mixing [20].

The plasma discharge was driven by an in-house custom-built half-bridge power supply operated at 2.3 $\mathrm{kV}_{\mathrm{pp}}$ and $19 \mathrm{kHz}$. To exercise control over the composition of reactive species produced in the plasma, the discharge was modulated by varying the duty cycle. The plasma on-time was varied between 100 ms to $1200 \mathrm{~ms}$ whereas the plasma off time was kept constant at $810 \mathrm{~ms}$. The duty cycle is then determined according to equation (1). A preliminary study demonstrated that higher duty cycles produce higher concentrations of reactive nitrogen species (RNS) species over reactive oxygen species (ROS) [14]. Therefore, the duty cycles used in this study were $10 \%, 45 \%$ and $60 \%$ with a corresponding power consumption of $4.4 \mathrm{~W}, 18.9 \mathrm{~W}$ and $24.4 \mathrm{~W}$ respectively. The power consumption for each duty cycle was determined from Lissajous diagrams [21].

$$
\text { Duty cycle }(\%)=\left(\frac{\text { on time }}{\text { on time }+ \text { off time }}\right) \times 100 \%
$$




\subsection{Measurements from the reactor}

Reactor performance was investigated by measuring ozone in the gas and the liquid phase. Gas phase measurements were taken by analysing the exhaust from a dry reactor with a gas flow cell (1-16m, Pike Technologies Inc. Madison, USA) coupled to a Fourier Transform Infrared Spectroscope (FTIR) (4700, Jasco Inc.). Ozone concentration in the liquid phase was measured using two aligned optical fibres within the liquid phase in the reactor. Transmitted light from one fibre (LLS-255, Ocean Optics Inc.) was collected by the receiving fibre and the intensity was measured by a spectrometer (HR2000+, Ocean Optics). The ozone concentration in the liquid phase was inferred from the Beer-Lambert law using an absorption coefficient of $3300 \mathrm{M}^{-1} \mathrm{~cm}^{-1}$ at $254 \mathrm{~nm}$ [22]. This measurement was only carried out in deionised water as the presence of bacteria and humic acid would affect the measurement. $\mathrm{pH}$ and temperature of the liquid phase was recorded using a combined meter (A215, Orion Star) during the experiments. The gas temperature within the plasma module was measured using a fibre optic thermometer (FOB102, Omega Inc.). The optical fibre was inserted to the plasma chamber through a sealable port on the side of the plasma module and data was recorded using a computer. For disinfection experiments, $500 \mathrm{ml}$ of water containing only E. coli or water containing both E. coli and humic acid was introduced to the reactor as appropriate. Dry compressed air was fed into the reactor and the plasma was turned on. Test samples were collected at 10-minute intervals for analysis.

\subsection{Bacterial cultivation}

E. coli (JHI5025) was provided by the James Hutton Institute, Dundee and cultured on Nutrient Agar (Oxoid, ThermoFisher UK) slopes containing nalidixic acid (30 mg/L). Prior to each experiment, 100 $\mathrm{ml}$ of Nutrient Broth (Oxoid, ThermoFisher UK) was inoculated with a loopful of cells from a slope and placed in a shaking incubator for 10 hours at $37^{\circ} \mathrm{C}$ at $120 \mathrm{rpm}$. Following this, $1 \mathrm{ml}$ of the broth was added to $450 \mathrm{ml}$ Nutrient Broth and incubated at the same conditions for 3 hours. The broth was then centrifuged at $3100 \mathrm{x}$ g for 10 minutes at room temperature. The supernatant was then poured off and the pellet re-suspended in $500 \mathrm{ml}$ of Ringer's solutions (Oxoid, ThermoFisher UK) to a concentration of $2.5 \times 10^{6} \mathrm{cfu} / \mathrm{ml}$ for treatment in the reactor. Humic acid (Sigma Aldrich, UK) was added to water 
as required for the final tests.

\subsection{Assessment of bacterial inactivation}

Water samples were taken for analysis from a sample port located on the lid of the reactor. The samples were diluted in Ringers solution and then plated onto Nutrient Agar (Oxoid, ThermoFisher UK). The Petri dishes were incubated for 24 hours at $37{ }^{\circ} \mathrm{C}$ before counting the number of colony forming units (CFUs) present. Prior to each disinfection experiment, a control experiment was conducted under identical conditions but with the plasma turned off.

\subsection{Results and discussion}

\subsection{Reactor performance}

FTIR measurements of the exhaust gas confirmed the production of both ROS and RNS, including ozone, $\mathrm{N}_{2} \mathrm{O}, \mathrm{N}_{2} \mathrm{O}_{5}$ and $\mathrm{HNO}_{3}$ as shown in Figure 2. However, some species such as $\mathrm{H}_{2} \mathrm{O}_{2}, \mathrm{HNO}_{2}$ and $\mathrm{NO}_{3}$ were not detected by the FTIR as their concentration fell below the detection limit or their peaks overlapped with other species. Once these reactive species are transferred to the liquid phase via microbubbles, they participate in chemical reactions to form various other species that are useful for the disinfection process. For instance, the reaction between ozone and $\mathrm{H}_{2} \mathrm{O}_{2}$ is crucial to bringing about effective disinfection as a result of the formation of $\mathrm{OH}^{\circ}$ [6]. Continuous in-situ production of $\mathrm{OH}^{\circ}$ within the treatment liquid is essential for this purpose as the half-life of $\mathrm{OH}^{\circ}$ is only of the order of 1 ns. Of these reactive species, only the concentration of ozone was measured in the liquid phase. Measuring radicals and other reactive species in the liquid phase is difficult due to their short lifetimes, the limited means of selectively identifying these species and the lack of optical access in the reactor. 


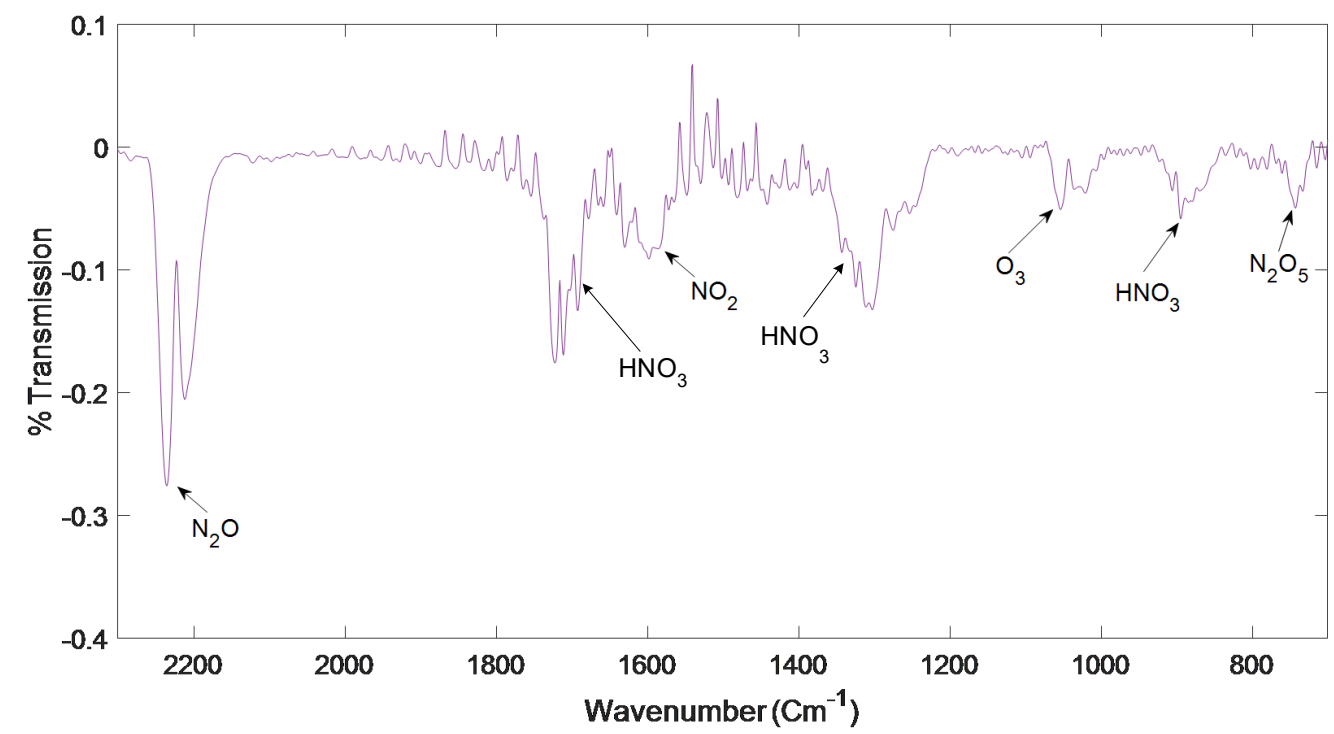

Figure 2: FTIR spectra of the principal ROS and RNS generated in the reactor

The concentration of ozone in the liquid phase for various duty cycles is shown in figure 3 (a). In all cases, the ozone concentration in the liquid increased with time, but the rate of increase in concentration started to drop for $10 \%$ and $45 \%$ duty cycles within the 30 -minute operation window as the mass transfer driving force is decreased. High duty cycles are capable of producing high levels of ozone in the plasma effluent due to the increase in input power, but the concentration could decrease due to thermal decomposition if the plasma temperature rises [23]. The gas temperature of the plasma module increased to $135^{\circ} \mathrm{C}$ and $107^{\circ} \mathrm{C}$ after 30 a minute run for $30 \%$ and $45 \%$ duty cycles respectively. For the 30 -minute characterization test shown in figure 3(b), the temperature of the water increased by $4^{\circ} \mathrm{C}$ for the $45 \%$ duty cycle compared to $1{ }^{\circ} \mathrm{C}$ for the $10 \%$ duty cycle. However, ozone concentration increased steadily for the higher duty cycle despite the temperature rise of both the gas and liquid phases. It was concluded that the plasma temperatures reached at the operating conditions used in this study after 30 minutes operation are still below the threshold for which thermal degradation outweighs the increased ozone generation as a result of an increase in power input. Therefore, if the disinfection process can be completed within a short period of time (less than 30 minutes), the effects temperature on ozone generation will be negligible. However, ozone solubility will be adversely affected by an increase in temperature of the liquid. If the process requires an extended time of operation at high duty cycles, 
additional external cooling may be required for the plasma module and the process liquid to maintain the desired dissolved ozone concentration.

The reactor was designed to provide natural cooling to enable operation at a relatively high duty cycle for maximum efficiency. The ground electrode (the membrane upon which bubble formation occurs) is cooled by liquid circulating above the membrane due to the air-lift loop effect and the quartz dielectric crucibles are cooled by the inlet air flow to the plenum. The former cooling mechanism is much more efficient than the latter as the gas residence time within the plenum for microbubble production is high. The liquid temperature rise is proportional to the duty cycle used, and at $60 \%$ duty cycle the liquid temperature rose by $5{ }^{\circ} \mathrm{C}$ after 30 minutes of operation (Figure 3(b)). This could be detrimental to efficient operation of the reactor for longer periods as ozone solubility decreases with liquid temperature. Hence, optimum reactor operating conditions need to be identified to avoid excessive heating of the liquid caused by the plasma, whilst still providing sufficient energy to produce high levels of ozone in the plasma effluent. In addition to the production of ROS and RNS, the plasma also emits UV at the gas-liquid interface. This emission leads to photochemical reactions that forms $\mathrm{OH}^{\circ}$ from the dissolved reactive species [6], in addition to bringing about direct disinfection in the vicinity of gas-liquid interface [24].
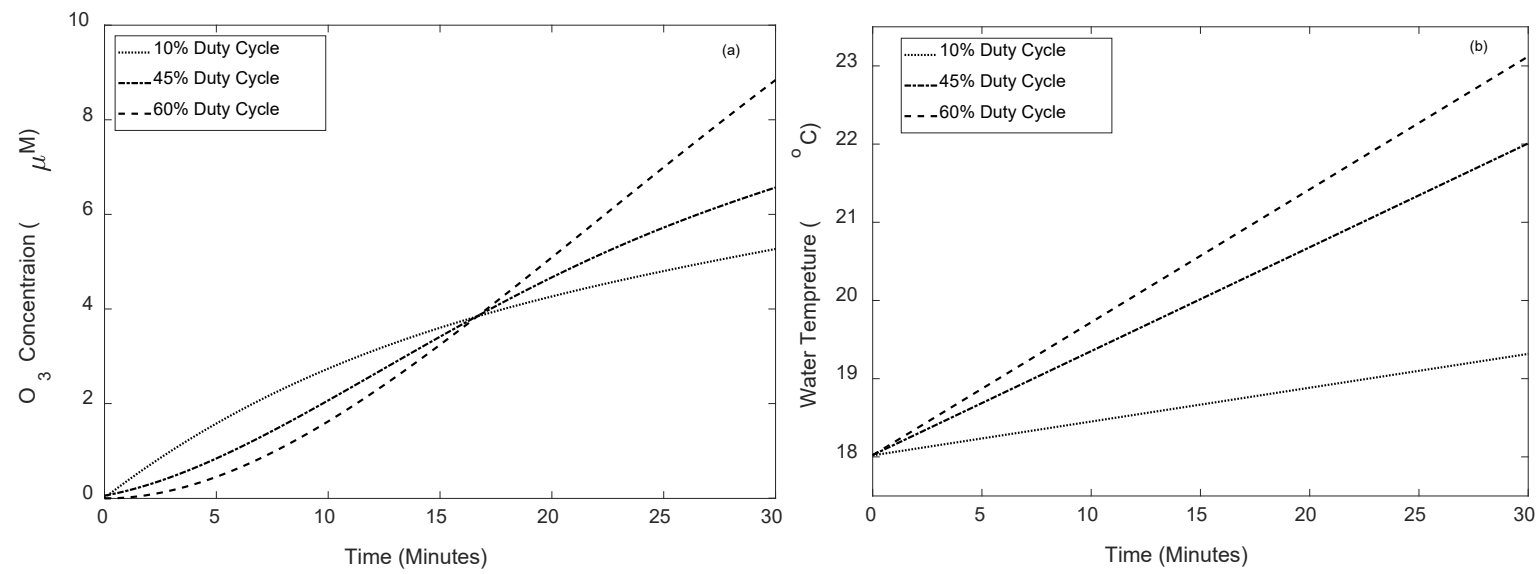

Figure 3: Reactor operating characteristics (a) ozone concentration in the liquid phase. (b) Reactor water 
temperature during the characterization experiment.

The $\mathrm{pH}$ profiles of the liquid for different duty cycles within a 30-minute run are shown in Figure 4. For the higher duty cycles tested (45\% and $60 \%)$, the pH dropped from 5.8 to 3.7 after 30 minutes of operation, mainly due to RNS and $\mathrm{H}_{2} \mathrm{O}_{2}$ dissolved in the liquid. For the lower duty cycle (10\%) the $\mathrm{pH}$ drop was slower reaching a final $\mathrm{pH}$ value of $\sim 5$. The significant drop in $\mathrm{pH}$ at relatively high duty cycles would be advantageous, as the solubility of both ozone and $\mathrm{H}_{2} \mathrm{O}_{2}$ increases under acidic conditions. Kim et al. reported a 2-log reduction in E. coli following a gliding arc plasma treatment, in which the $\mathrm{pH}$ remained low $(\sim 3.5 \mathrm{pH})$ for $2-4 \mathrm{hr}$ during the storage period [13]. The residual combined effect of $\mathrm{H}_{2} \mathrm{O}_{2}$ and low-pH was highlighted in this study as an effective approach to improving the inactivation of $E$. coli.

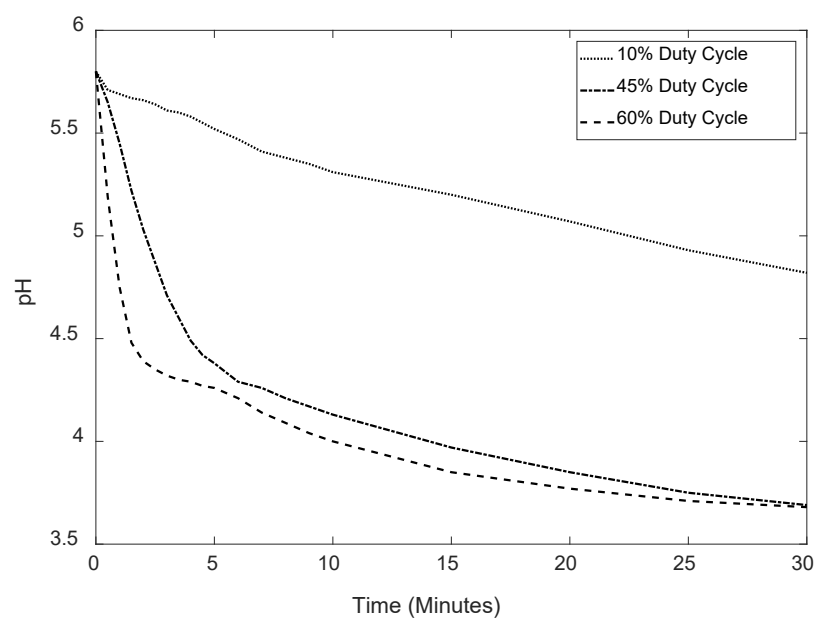

Figure 4: The change in $\mathrm{pH}$ during reactor operation for the three duty cycles employed.

\subsection{Inactivation of E. coli}

Initially, the reactor was run with Ringers solution prepared using deionised water in which E. coli was suspended, but without the presence of dissolved organic matter, to determine the maximum disinfection rate achievable. The effects of the duty cycle and the treatment time on disinfection are shown in Figure 5. A control experiment was conducted by operating the reactor with the plasma discharge turned off. 


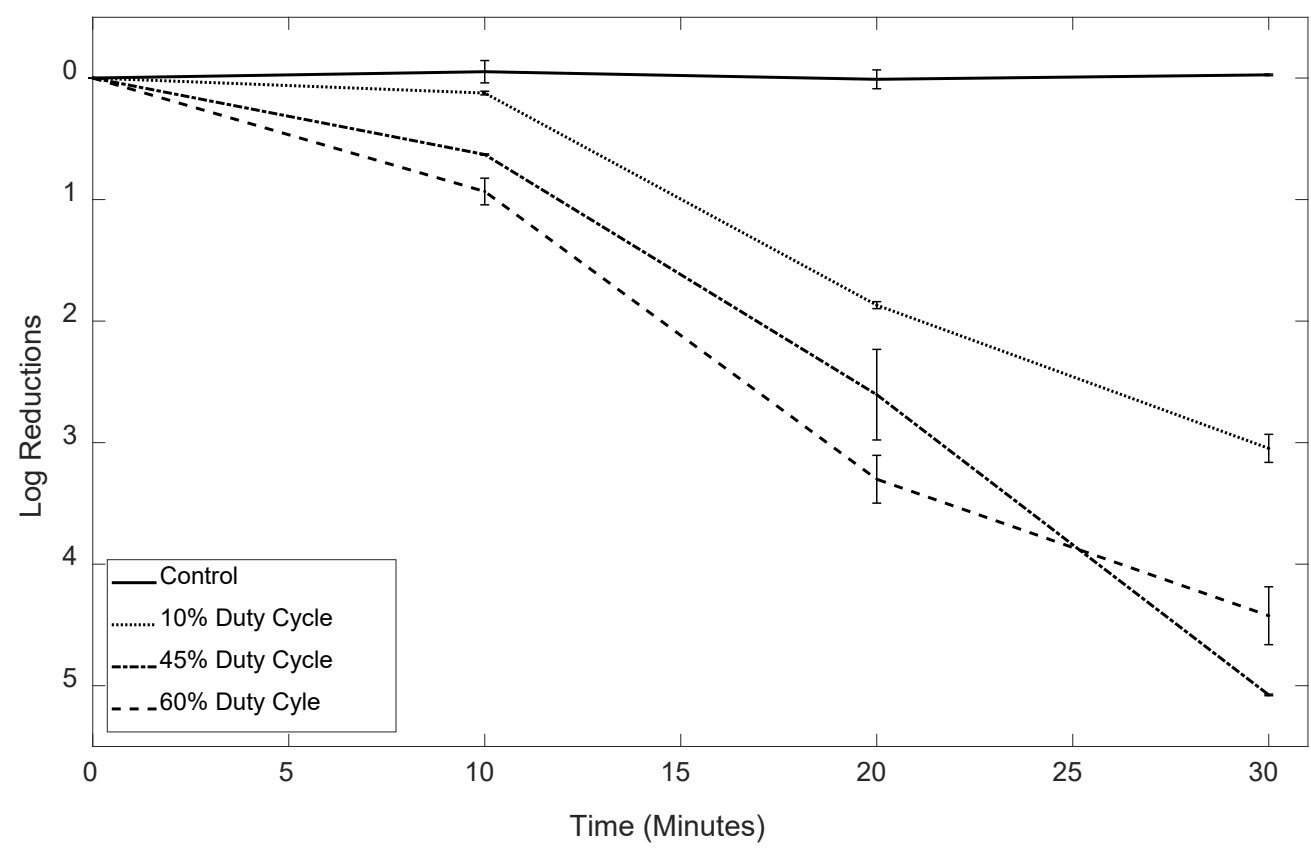

Figure 5: The effect of duty cycle on inactivation of E. coli in the plasma-microbubble reactor. The error bars represent standard deviation of triplicate samples.

Figure 5 shows that microbubbles alone cannot inactivate $E$. coli. The microbubbles generated ranged from $\sim 200 \mu \mathrm{m}$ to $\sim 500 \mu \mathrm{m}$ in diameter and would rise slowly in the test liquid due to buoyant forces and leave gas-liquid interface. However, studies have been reported where smaller microbubbles having diameters of $\sim 50 \mu \mathrm{m}$ or less collapse in water to produce $\mathrm{OH}^{\circ}$ [25]. In this study, microbubble production was tuned to produce sufficiently large bubbles to induce liquid recirculation whilst keeping them small enough to provide a substantial surface to volume ratio to achieve high mass transfer rates. This provides evidence that the bacterial inactivation achieved under normal operation of the reactor was a consequence of reactive species transferred to the liquid via the microbubbles. With the plasma turned on, all duty cycles demonstrated substantial reduction in E. coli viability. The rate of disinfection was relatively low for the first 10 minutes compared to subsequent operation and this is due to the initially low concentration of ROS and RNS in the liquid phase. Similar disinfection rates were observed for all three duty cycles from 10 to 20 -minute time interval suggesting that the reactor operates at a comparable efficiency over this period. The most effective duty cycle for bacterial inactivation up to 20 minutes was $60 \%$ followed by $45 \%$ and $10 \%$. However, this trend was reversed 
at the final time point of 30 minutes where the disinfection level achieved with $60 \%$ duty cycle was surpassed by that of $45 \%$ duty cycle. These results demonstrate the dynamic nature of the reactor, particularly the effect of heat accumulation over time and the consequent changes in reactive species generated. Ozone is the main oxidative species produced in this reactor, but other ROS and RNS also contribute to bacterial inactivation. Despite the fact that the highest ozone concentration was achieved with $60 \%$ duty cycle (Figure 3 ), it emerged that the optimum mixture of reactive species for bacterial inactivation was achieved at a $45 \%$ duty cycle during the 30 -minute operation. The biocidal effects of ROS and RNS have been well established and their production rate depends on the duty cycle used and conditions within the plasma module $[19,26]$. For a $45 \%$ duty cycle, the disinfection level exceeded 5$\log$ reductions after a 30-minute treatment time demonstrating the effectiveness of this approach.

\subsection{Effect of humic acid on inactivation of E. coli}

The majority of previous studies on AOP treatment of bacterial suspensions in liquids were conducted either in deionised water or in buffered deionised water, which is not representative of actual municipal or industrial effluents. The HA concentration was varied from $0 \%$ to $1.5 \times 10^{-3} \%(\mathrm{w} / \mathrm{w})$. These concentrations are within the range typical of wastewater effluents [18] and within the range employed in previous studies focusing on HA removal from water [5,27].

Inactivation of $E$. coli in the microbubble-gas plasma reactor in the presence of HA is shown in Figure 6. The duty cycle was fixed at $45 \%$ for these experiments as this power configuration provided the maximum number of $\log$ reductions within a 30 -minute interval for clean water tests. In the first 10 minutes of plasma treatment, no significant diminution in the rate of disinfection was observed at low concentrations of HA, but at the highest HA concentration tested a lower rate of disinfection was observed. The rate of disinfection increases with time as reactive species accumulate in the liquid for all HA concentrations. However, the number of log reductions achieved in each case was clearly influenced by the HA concentration. HA is an organic compound that reacts with ROS and RNS transferred to the liquid phase thereby quenching reactive species available for disinfection [17]. As a 
result, the decreasing inactivation rate of $E$. coli is directly proportional to increasing HA concentration in the liquid medium. This result suggests that the residence time in a treatment reactor should be adjusted to match the organic matter concentration in the liquid to achieve the desired level of disinfection. For instance, the level of disinfection achieved with an HA concentration of $0.0015 \%$ in 30 minutes can be achieved in only 20 minutes with clean water.

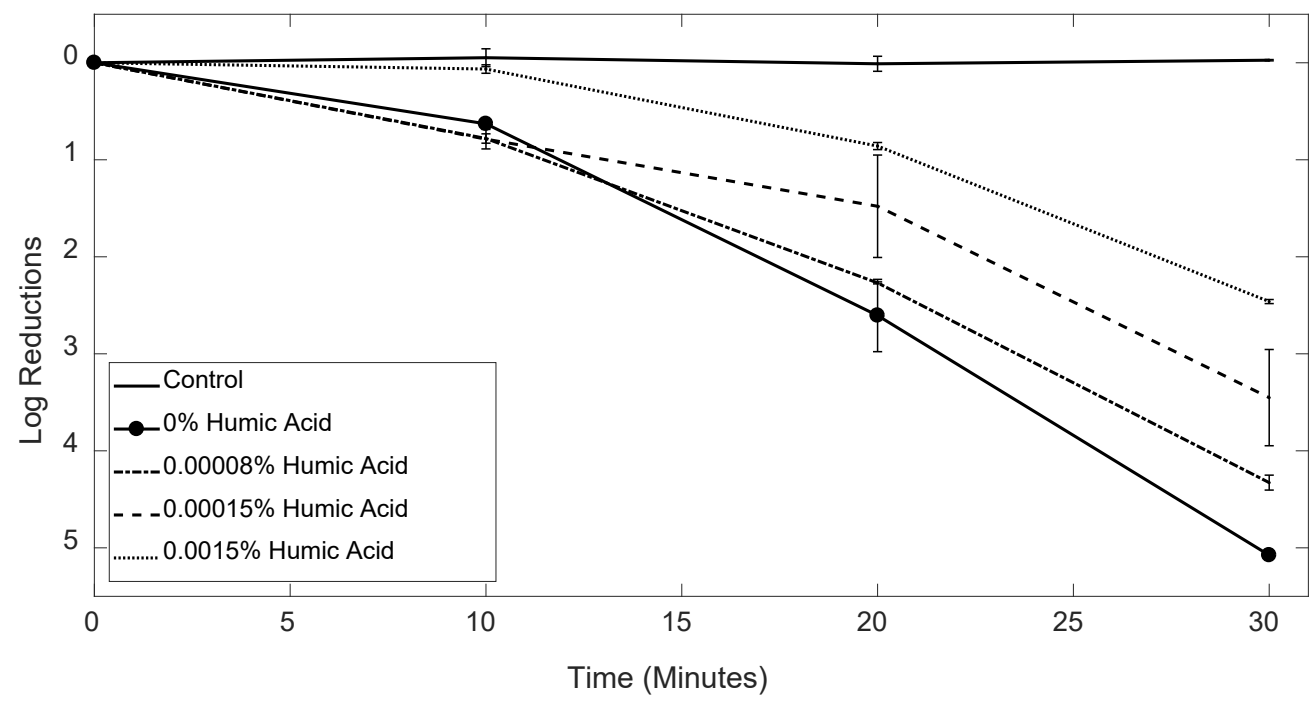

Figure 6: Inactivation of $E$. coli in the microbubble-plasma reactor in the presence of $\mathrm{HA}$ at $45 \%$ duty cycle. The error bars represent standard deviation of triplicate samples.

\subsection{Comparison of power consumption}

Direct comparison of the performance of AOP reactors for the inactivation of E. coli is not straightforward due to various factors such as differences in E. coli strains used, reactor volume, treatment time and power input. Energy consumption and scalability are key factors in assessing whether a particular treatment technology is suitable for industrial use. Similar reactor technologies previously used for inactivation of E. coli, their power consumption figures are presented in Table 1 and their key features are compared with this study. An off-gas sparging treatment based on a multineedle electrode configuration was reported by Wang et al. [28] where $120 \mathrm{ml}$ of buffered distilled water was treated for 10 minutes to achieve a 6-log reduction in E. coli consuming $180 \mathrm{~kJ} / \mathrm{L}$. This traditional approach of using two separate reactors, one to produce ozone and another for liquid 
treatment, may be less efficient compared to in-situ generation as short-lived reactive species will be eliminated by the time the reactive species generated by the plasma reach the liquid in the former case. Kim et al. reported synergistic effects of $\mathrm{H}_{2} \mathrm{O}_{2}$ and low $\mathrm{pH}$ conditions produced by a gliding arc (GA) discharge reactor for the inactivation of $E$. coli [13]. Microbubbles were used to improve the contact between $\mathrm{H}_{2} \mathrm{O}_{2}$ and $E$. coli, and the process led to an energy consumption of $15 \mathrm{~kJ} / \mathrm{L}$ in the treatment of $20 \mathrm{~L}$ of liquid. However, the need for water injection to the gliding arc could significantly increase the operating energy costs on scale-up. A packed-bed discharge plasma reactor that achieves efficient contact between solids, liquid and air has been evaluated using ferroelectric pellets [16]. The proximity of the plasma to the gas-liquid interface and the micro-discharges on the pellets led to an effective disinfection process, but the suitability of this approach under industrial conditions is questionable as fouling on the pellets could significantly reduce active plasma sites and eventually reduce the efficiency of microbial inactivation. Power consumption data for this study was not reported. Huang et al. [29] used a streamer plasma in water to produce radicals for the inactivation of E. coli and found that the inactivation rate depended on the input energy density. A nanosecond pulsed power supply was used in this study to produce ozone and the energy consumption was estimated to be $8 \mathrm{~kJ} / \mathrm{L}$. HernándezArias et al. [10] used a pulsed dielectric barrier discharge atmospheric pressure plasma to inactivate $E$. coli using ozone. Oxygen bubbles were introduced to promote mixing of the liquid and to maximize ozone production, but species transport was limited to the free surface of the liquid leading to a high energy consumption of $2002 \mathrm{~kJ} / \mathrm{L}$. The microbubble-gas plasma reactor used in the study reported here consumed $68 \mathrm{~kJ} / \mathrm{L}$ in the achievement of a $5 \log$-reduction in $E$. coli demonstrating the efficacy of this approach compared to the performance of alternative reactor designs as previously reported in the literature. 
Table 1: Energy usage of plasma-based reactors for water disinfection

\begin{tabular}{|l|c|c|c|c|c|c|}
\hline \multicolumn{1}{|c|}{ Study } & $\begin{array}{c}\text { Power } \\
\text { consumption } \\
(\mathrm{W})\end{array}$ & $\begin{array}{c}\text { Treatment } \\
\text { time (min) }\end{array}$ & $\begin{array}{c}\text { Treated liquid } \\
\text { volume (ml) }\end{array}$ & $\begin{array}{c}\text { Energy usage } \\
(\mathrm{kJ} / \mathrm{L})\end{array}$ & $\begin{array}{c}\text { Log } \\
\text { reductions }\end{array}$ & Reference \\
\hline Microbubble-plasma reactor & 18.9 & 30 & 500 & 68 & 5 & $\begin{array}{c}\text { This } \\
\text { study }\end{array}$ \\
\hline $\begin{array}{l}\text { Off-gas from pulsed-discharge } \\
\text { plasma generated in a multi- } \\
\text { needle electrode configuration } \\
\text { used for basic sparging }\end{array}$ & 36 & 10 & 120 & 180 & 5 & {$[28]$} \\
\hline $\begin{array}{l}\text { Both air and distilled water } \\
\text { passing through a GA discharge } \\
\text { dispersed using microbubbles }\end{array}$ & 200 & 25 & 20 & 15 & 4 & {$[13]$} \\
\hline $\begin{array}{l}\text { Multiple-needle-cylinder } \\
\text { reactor with an unstable pulsed } \\
\text { arc discharge in water }\end{array}$ & 8 & 5 & 300 & 8 & 3 & {$[29]$} \\
\hline Pulsed DBD with oxygen bubbles & 50 & 10 & 15 & 2002 & 3 & {$[10]$} \\
\hline $\begin{array}{l}\text { Transient spark electro spray flow } \\
\text { reactor }\end{array}$ & 2 & $0.5 \mathrm{ml} / \mathrm{m}$ (flow system) & 6.2 & 6 & {$[30]$} \\
\hline
\end{tabular}

As demonstrated in table 1, the type of plasma used, the reactor configuration and the reactor volume affect the overall efficiency of the disinfection process. Therefore, it is important to assess the suitability of plasma-microbubble approach in scaling up the reactor from bench scale to pilot and industrial scale while maintaining high efficiencies reported in this study. The air-lift loop reactor technology implemented for low-cost mixing has been reported in the literature for pilot scale bioreactors ( $\sim 250 \mathrm{~L})$ demonstrating its potential for scale-up [20]. In addition, it would be possible to integrate fluidic oscillator mediated energy efficient microbubble generation technology to this reactor to enhance the mass transfer of reactive species [19]. Rehman et al. demonstrated the advantages of using energy-efficient microbubbles in the treatment of wastewater on the basis of improved mass transfer coefficients, mixing efficiency and energy efficiency [31] and this technology has been tested at pilot scale waste water treatment plants. It is envisaged that integration of plasma modules within sparger plenum chambers would enable efficient large-scale treatment of wastewaters. 


\subsection{Conclusions}

Forming a DBD plasma at the gas-liquid interface allows efficient transfer of reactive species from the plasma to the liquid phase. Operation of the microbubble-gas plasma reactor at a duty cycle of $45 \%$ achieved a 5-log reduction in $E$. coli viability in deionised water after 30 minutes of operation, but the presence of humic acid reduced the disinfection rate to an extent that was dependant on its concentration. Low power consumption of the plasma and efficient dispersal of reactive species using microbubbles were key features of this reactor. This approach has a potential to scale-up and could be used in the treatment of both municipal and industrial final effluents.

\section{Acknowledgements}

The authors would like to thank Plants to Products BBSRC NIBB for funding (POC-HD_RD0300 C). HB would like to acknowledge Micropore Technology Ltd. for providing nickel membranes and Perlemax Ltd. for advice and support on plasma reactors. AW would like to acknowledge the school of ACCME, Loughborough University and EPSRC (EP/M507908/1) for his PhD studentship.

\section{References}

[1] M. Ferri, E. Ranucci, P. Romagnoli, V. Giaccone, Antimicrobial resistance: A global emerging threat to public health systems, Crit. Rev. Food Sci. Nutr. 57 (2017) 2857-2876. doi:10.1080/10408398.2015.1077192.

[2] WHO, WHO Global Strategy for Containment of Antimicrobial Strategy for Containment of Antimicrobial Resistance, 2001. doi:WHO/CDS/CSR/DRS/2001.2 99 p.

[3] C.W. McKinney, A. Pruden, Ultraviolet disinfection of antibiotic resistant bacteria and their antibiotic resistance genes in water and wastewater, Environ. Sci. Technol. 46 (2012) 13393-13400. doi:10.1021/es303652q.

[4] B. Langlain, D. Reckhow, D. Brink, Ozone in Water Treatment: Application and Engineering, 1991.

[5] O. González, A. Justo, J. Bacardit, E. Ferrero, J.J. Malfeito, C. Sans, Characterization and fate of effluent organic matter treated with UV/H2O2 and ozonation, Chem. Eng. J. 226 (2013) 402-408. 
doi:10.1016/j.cej.2013.04.066.

[6] E.J. Rosenfeldt, K.G. Linden, S. Canonica, U. von Gunten, Comparison of the efficiency of OH radical formation during ozonation and the advanced oxidation processes $\mathrm{O} 3 / \mathrm{H} 2 \mathrm{O} 2$ and UV/H2O2., Water Res. 40 (2006) 3695-3704. doi:10.1016/j.watres.2006.09.008.

[7] U. Von Gunten, Ozonation of drinking water: Part I. Oxidation kinetics and product formation, Water Res. 37 (2003) 1443-1467. doi:10.1016/S0043-1354(02)00457-8.

[8] Y. Sakiyama, D.B. Graves, H.-W. Chang, T. Shimizu, G.E. Morfill, Plasma chemistry model of surface microdischarge in humid air and dynamics of reactive neutral species, J. Phys. D. Appl. Phys. 45 (2012) 425201. doi:10.1088/0022-3727/45/42/425201.

[9] N. Bai, P. Sun, H. Zhou, H. Wu, R. Wang, F. Liu, W. Zhu, J.L. Lopez, J. Zhang, J. Fang, Inactivation of Staphylococcus aureus in Water by a Cold, He/O2 Atmospheric Pressure Plasma Microjet, Plasma Process. Polym. 8 (2011) 424-431. doi:10.1002/ppap.201000078.

[10] A.N. Hernández-Arias, B.G. Rodríguez-Méndez, R. López-Callejas, D. Alcántara-Díaz, R. ValenciaAlvarado, A. Mercado-Cabrera, R. Peña-Eguiluz, A.E. Muñoz-Castro, S.R. Barocio, A. de la PiedadBeneitez, Inactivation of Escherichia coli in water by pulsed dielectric barrier discharge in coaxial reactor, J. Water Health. 10 (2012) 371. doi:10.2166/wh.2012.132.

[11] C.A.J. van Gils, S. Hofmann, B.K.H.L. Boekema, R. Brandenburg, P.J. Bruggeman, Mechanisms of bacterial inactivation in the liquid phase induced by a remote RF cold atmospheric pressure plasma jet, J. Phys. D. Appl. Phys. 46 (2013) 175203. doi:10.1088/0022-3727/46/17/175203.

[12] M. Laroussi, J.P. Richardson, F.C. Dobbs, Effects of nonequilibrium atmospheric pressure plasmas on the heterotrophic pathways of bacteria and on their cell morphology, Appl. Phys. Lett. 81 (2002) 772774. doi:10.1063/1.1494863.

[13] H.S. Kim, Y.I. Cho, I.H. Hwang, D.H. Lee, D.J. Cho, A. Rabinovich, A. Fridman, Use of plasma gliding arc discharges on the inactivation of E. Coli in water, Sep. Purif. Technol. 120 (2013) 423-428. doi:10.1016/j.seppur.2013.09.041.

[14] A. Wright, H. Bandulasena, C. Ibenegbu, D. Leak, T. Holmes, W. Zimmerman, A. Shaw, F. Iza, Dielectric barrier discharge plasma microbubble reactor for pretreatment of lignocellulosic biomass, AIChE J. 64 (2018) 3803-3816. doi:10.1002/aic.16212.

[15] P. Andre, J. Aubreton, Y. Barinov, M.F. Elchinger, P. Fauchais, G. Faure, V. Kaplan, A. Lefort, V. Rat, 
S. Shkol'nik, Theoretical study of column of discharge with liquid non-metallic (tap water) electrodes in air at atmospheric pressure, J. Phys. D. Appl. Phys. 35 (2002) 305. doi:10.1088/0022-3727/35/15/305.

[16] C. hua Wang, Y. Wu, G. feng Li, Inactivation of E. coli with plasma generated by bipolar pulsed discharge in a three-phase discharge plasma reactor, J. Electrostat. 66 (2008) 71-78. doi:10.1016/j.elstat.2007.08.002.

[17] T. Wang, G. Qu, J. Ren, Q. Yan, Q. Sun, D. Liang, S. Hu, Evaluation of the potentials of humic acid removal in water by gas phase surface discharge plasma, Water Res. 89 (2016) 28-38. doi:10.1016/j.watres.2015.11.039.

[18] A. Imai, T. Fukushima, K. Matsushige, Y.-H. Kim, K. Choi, Characterization of dissolved organic matter in effluents from wastewater treatment plants, Water Res. 36 (2002) 859-870. doi:10.1016/S00431354(01)00283-4.

[19] A. Wright, M. Taglioli, F. Montazersadgh, A. Shaw, F. Iza, H.C.H. Bandulasena, Microbubble-enhanced DBD plasma reactor: Design, characterisation and modelling, Chem. Eng. Res. Des. 144 (2019) 159173. doi:10.1016/j.cherd.2019.01.030.

[20] W.B. Zimmerman, B.N. Hewakandamby, V. Tesar̆, H.C.H. Bandulasena, O.A. Omotowa, On the design and simulation of an airlift loop bioreactor with microbubble generation by fluidic oscillation, Food Bioprod. Process. 87 (2009) 215-227. doi:10.1016/j.fbp.2009.03.006.

[21] T.C. Manley, The Electric Characteristics of the Ozonator Discharge, Trans. Electrochem. Soc. 84 (1943) 83. doi:10.1149/1.3071556.

[22] C.I. Koh, S.J. Lee, J.W. Kang, New UV-flux measurement method using ozone photolysis rate, OzoneScience Eng. 23 (2001) 245-253. doi:10.1080/01919510108962008.

[23] T. Ma, H. Jiang, J. Liu, F. Zhong, Decomposition of Benzene Using a Pulse-Modulated DBD Plasma, Plasma Chem. Plasma Process. 36 (2016) 1533-1543. doi:10.1007/s11090-016-9736-z.

[24] A. Shaw, P. Seri, C.A. Borghi, G. Shama, F. Iza, A reference protocol for comparing the biocidal properties of gas plasma generating devices, J. Phys. D. Appl. Phys. 48 (2015) 484001. doi:10.1088/0022-3727/48/48/484001.

[25] M. Takahashi, K. Chiba, P. Li, Free-radical generation from collapsing microbubbles in the absence of a dynamic stimulus, J. Phys. Chem. B. 111 (2007) 1343-1347. doi:10.1021/jp0669254.

[26] J. Hayes, D. Kirf, M. Garvey, N. Rowan, Disinfection and toxicological assessments of pulsed UV and 
pulsed-plasma gas-discharge treated-water containing the waterborne protozoan enteroparasite Cryptosporidium parvum, J. Microbiol. Methods. 94 (2013) 325-337. doi:10.1016/j.mimet.2013.07.012.

[27] D. Imai, A.H.A. Dabwan, S. Kaneco, H. Katsumata, T. Suzuki, T. Kato, K. Ohta, Degradation of marine humic acids by ozone-initiated radical reactions, Chem. Eng. J. 148 (2009) 336-341. doi:10.1016/j.cej.2008.09.013.

[28] K. Satoh, S.J. MacGregor, J.G. Anderson, G.A. Woolsey, R.A. Fouracre, Pulsed-plasma disinfection of water containing Escherichia coli, Japanese J. Appl. Physics, Part 1 Regul. Pap. Short Notes Rev. Pap. 46 (2007) 1137-1141. doi:10.1143/JJAP.46.1137.

[29] Y. Huang, Y. Kou, C. Zheng, Y. Xu, Z. Liu, K. Yan, Escherichia Coli Inactivation in Water Using Pulsed Discharge, IEEE Trans. Plasma Sci. 44 (2016) 938-943. doi:10.1109/TPS.2016.2559802.

[30] Z. Machala, B. Tarabová, D. Sersenová, M. Janda, K. Hensel, Chemical and antibacterial effects of plasma activated water: correlation with gaseous and aqueous reactive oxygen and nitrogen species, plasma sources and air flow conditions, J. Phys. D. Appl. Phys. 52 (2019) 034002. doi:10.1088/13616463/aae807.

[31] F. Rehman, G.J.D. Medley, H.C.H. Bandulasena, W.B. Zimmerman, Fluidic oscillator-mediated microbubble generation to provide cost effective mass transfer and mixing efficiency to the wastewater treatment plants, Environ. Res. 137 (2015) 32-39. doi:10.1016/j.envres.2014.11.017. 